\title{
Myocardial fibrosis is associated with subsequent death and hospitalization for heart failure in obese adults
}

\author{
Yaron Fridman ${ }^{1,2}$, Timothy C Wong ${ }^{1,2}$, Kayla M Piehler ${ }^{1,2}$, Karolina M Zareba ${ }^{1,2}$, James Moon ${ }^{3}$, Martin Ugander ${ }^{4}$, \\ Daniel Messroghli ${ }^{5}$, John M Jakicic ${ }^{13^{*}}$, Uma Valeti ${ }^{6}$, Chung-Chou Chang ${ }^{7}$, Sanjeev G Shroff ${ }^{8}$, Christopher A Miller ${ }^{9}$, \\ Matthias Schmitt ${ }^{9}$, Peter Kellman ${ }^{10}$, Javed Butler ${ }^{11}$, Mihai Gheorghiade ${ }^{12}$, Erik B Schelbert ${ }^{1,2}$
}

From 18th Annual SCMR Scientific Sessions

Nice, France. 4-7 February 2015

\section{Background}

Cardiac imaging in obese adults poses significant technical challenges, yet the prognostic value of diffuse myocardial fibrosis in obese adults quantified with cardiovascular magnetic resonance (CMR) extracellular volume fraction (ECV) measures is unknown. This issue is important because obesity increases the risks of death and hospitalization for heart failure (HHF). Myocardial fibrosis measured in obese adults with ECV may indicate vulnerability to death and HHF.

\section{Methods}

We enrolled 480 consecutive obese patients with a BMI $>30$ referred for cardiovascular magnetic resonance (CMR) without amyloidosis, stress cardiomyopathy, or hypertrophic cardiomyopathy. We quantified myocardial fibrosis with CMR ECV measures in noninfarcted myocardium. Patient data, BMI, hematocrit, were collected on the day of CMR, and we tracked outcomes prospectively.

\section{Results}

Median BMI was 35 (IQR 32-41), and median ECV was 27.7\% (IQR 25.6\%-30.9\%, range). BMI and ECV were not related $(\mathrm{p}=0.90)$. Over a median 1.5 years (IQR 0.92.5yrs), 27 HHF events and 28 deaths occurred after CMR in 50 individuals. Adjusting for age, gender, renal function, myocardial infarction size, ejection fraction, hospitalization status, and heart failure stage, ECV in obese adults was associated with HHF (HR1.92 95\%CI 1.40-2.65 for every 5\% increase in ECV (ECV range:

\footnotetext{
${ }^{13}$ Health and Physical Activity, University of Pittsburgh, Pittsburgh, PA, USA
} Full list of author information is available at the end of the article
16.6-45.8), death (HR 2.50 95\%CI 1.59-3.95) or both (HR1.97 95\%CI 1.44-2.70). ECV improved the classification of obese adults at risk and improved model discrimination for the composite outcome: e.g., HHF or death [continuous net reclassification improvement (NRI) 0.429, 95\% CI 0.063-0.758; $\mathrm{p}=0.02$; integrated discrimination improvement (IDI) $0.069,95 \%$ CI $0.016-0.132$; $\mathrm{p}=0.02]$.

\section{Conclusions}

Despite the challenges of cardiac imaging in obese adults, diffuse myocardial fibrosis quantified by ECV is associated with HHF, death, or both. Myocardial fibrosis may represent a principal marker of cardiac vulnerability that improves risk stratification even in the setting of obesity. Since myocardial fibrosis can be reversible, myocardial fibrosis and the fibroblast that regulates it may be attractive therapeutic targets in obese patients.

\section{Funding}

Dr. Schelbert was supported by a grant from The Pittsburgh Foundation,Grant M2009-0068, and an American Heart Association Scientist Development grant (09SDG2180083) including a T. Franklin Williams Scholarship Award; funding provided by: Atlantic Philanthropies, Inc., the John A. Hartford Foundation, the Association of Specialty Professors, and the AHA. Dr. Wong was supported by a grant K12 HS19461-01 from the AHRQ. Dr. Shroff's research was supported by the McGinnis Endowed Chair funds. This work was also supported by Grant Number UL1 RR024153 from the National Center for Research Resources (NCRR), NIH. 


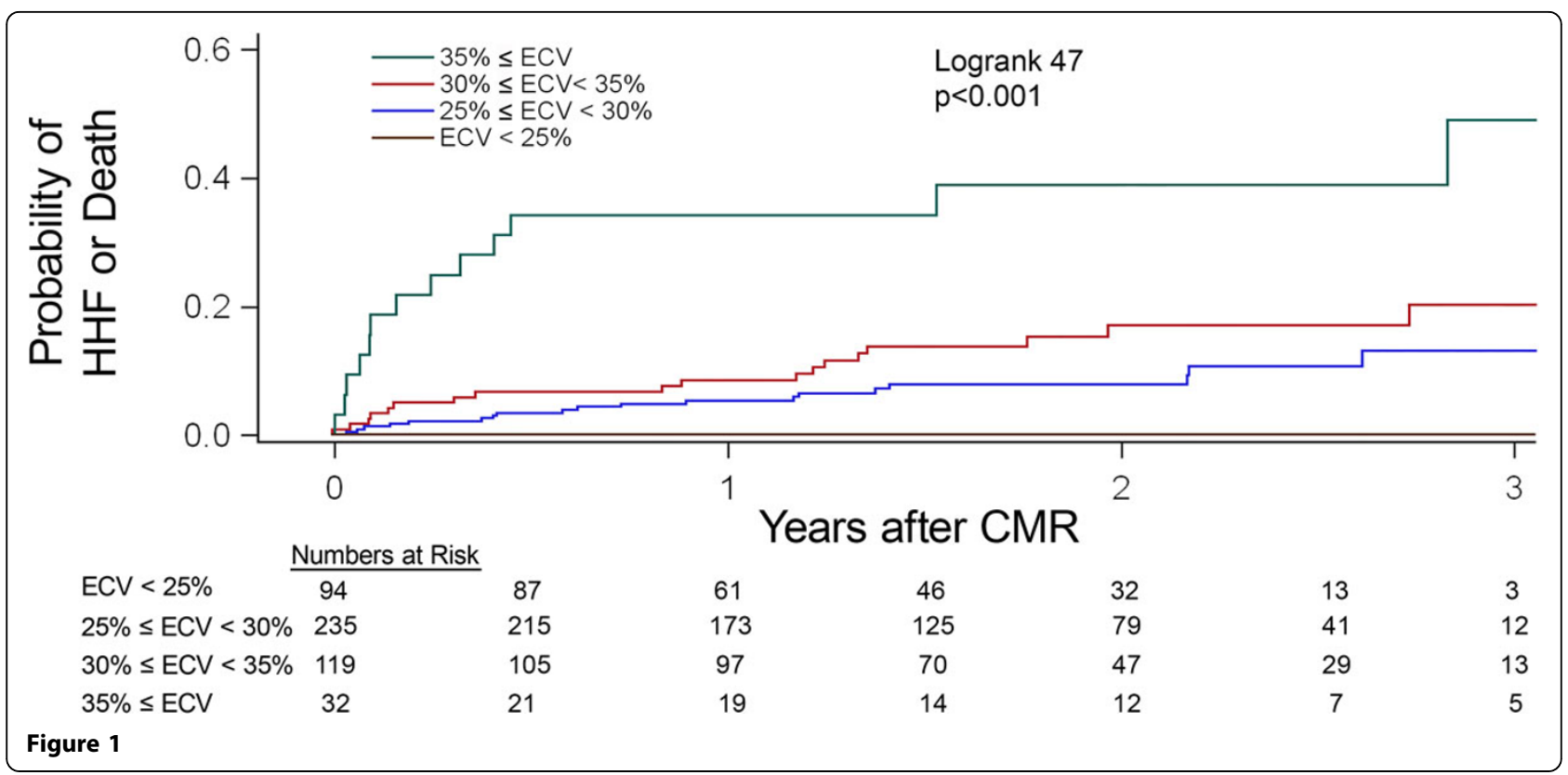

Table 1 In multivariable models, EC in noninfarcted myocardium in obese patients remained associated with the combined endpoint of HHF/death. The addition of ECV improved the classification of individuals at risk (new reclassification improvement, NRI) and the discrimination of the model (integrated discrimination improvement, IDI).

\begin{tabular}{|c|c|c|c|c|}
\hline Multivariable Cox regression model & $\begin{array}{l}\text { Hazard Ratio for every } \\
5 \% \text { increase in ECV }(95 \% \\
\text { Cl; } p \text { value) }\end{array}$ & $\begin{array}{l}\text { Category free } \\
\text { NRI }(95 \% \mathrm{Cl} ; \mathrm{p} \\
\text { value) }\end{array}$ & $\begin{array}{l}\text { Categorical NRI } 0, .05 \\
0.10 \text { risk categories } \\
(95 \% \mathrm{Cl}) ; \mathrm{p} \text { value })\end{array}$ & $\begin{array}{l}\text { IDI }(95 \% \\
\text { Cl; } p \\
\text { value) }\end{array}$ \\
\hline $\begin{array}{l}\text { Modeling composite of HHF or death, } \\
\text { stratified by heart failure stage and hospitalization } \\
\text { status, adjusted for EF, age, glomerular filtration rate, } \\
\text { myocardial infarction size, and gender }\end{array}$ & $\begin{array}{l}1.97 \\
(1.44-2.70 ; p<0.001)\end{array}$ & $\begin{array}{l}0.43 \\
(0.06-0.76 \\
p=0.02)\end{array}$ & $\begin{array}{l}0.04 \\
(0.005-0.079 ; p=0.02)\end{array}$ & $\begin{array}{l}0.069 \\
(0.016- \\
0.132 \\
p=0.02)\end{array}$ \\
\hline
\end{tabular}

\section{Authors' details}

${ }^{1}$ Cardiology, Heart and Vascular Institute, UPMC, Pittsburgh, PA, USA. ${ }^{2}$ UPMC

Cardiovascular Magnetic Resonance Center, Pittsburgh, PA, USA. ${ }^{3}$ University

College of London, Heart Hospital Imaging Centre, London, UK. ${ }^{4}$ Clinical

Physiology, Karolinska Institutet and Karolinska University Hospital,

Stockholm, Sweden. ${ }^{5}$ Congenital Heart Disease and Pediatric Cardiology,

Deutsches Herzzentrum Berlin, Berlin, Germany. ${ }^{6}$ Cardiology Division,

University of Minnesota, Minneapolis, MN, USA. 'Biostatistics, University of

Pittsburgh Graduate School of Public Health, Pittsburgh, PA, USA.

${ }^{8}$ Bioengineering, University of Pittsburgh, Pittsburgh, PA, USA. ${ }^{9}$ Centre for Imaging Sciences and Biomedical Imaging Institute, University of

Manchester, Manchester, UK. ${ }^{10}$ National Heart, Lung, and Blood Institute, Bethesda, MD, USA. ${ }^{11}$ Cardiology Division, Emory University, Atlanta, GA, USA.

${ }^{12}$ Center for Cardiovascular Innovation, Northwestern University Feinberg School of Medicine, Chicago, IL, USA. ${ }^{13}$ Health and Physical Activity, University of Pittsburgh, Pittsburgh, PA, USA.

Published: 3 February 2015

doi:10.1186/1532-429X-17-S1-M8

Cite this article as: Fridman et al: Myocardial fibrosis is associated with subsequent death and hospitalization for heart failure in obese adults. Journal of Cardiovascular Magnetic Resonance 2015 17(Suppl 1):M8.

Submit your next manuscript to BioMed Central and take full advantage of:

- Convenient online submission

- Thorough peer review

- No space constraints or color figure charges

- Immediate publication on acceptance

- Inclusion in PubMed, CAS, Scopus and Google Scholar

- Research which is freely available for redistribution 